\title{
Treatment trends in allergic rhinitis and asthma: a British ENT survey
}

\author{
Ravinder S Natt ${ }^{1 *}$, Petros D Karkos ${ }^{2}$, Davinia K Natt ${ }^{4}$, Eva G Theochari ${ }^{3}$ and Apostolos Karkanevatos ${ }^{1}$
}

\begin{abstract}
Background: Allergic Rhinitis is a common Ear, Nose and Throat disorder. Asthma and Allergic Rhinitis are diseases with similar underlying mechanism and pathogenesis. The aim of this survey was to highlight current treatment trends for Allergic Rhinitis and Asthma.

Method: A questionnaire was emailed to all registered consultant members of the British Association of Otorhinolaryngologists - Head and Neck Surgeons regarding the management of patients with Allergic Rhinitis and related disorders.
\end{abstract}

Results: Survey response rate was $56 \%$. The results indicate a various approach in the investigation and management of Allergic Rhinitis compatible with recommendations from the Allergic Rhinitis and Its Impact on Asthma guidelines in collaboration with the World Health Organisation.

Conclusion: A combined management approach for patients with Allergic Rhinitis and concomitant Asthma may reduce medical treatment costs for these conditions and improve symptom control and quality of life.

Keywords: Allergic Rhinitis Asthma, Survey, Questionnaire, Atopy

\section{Background}

The definition of Allergic Rhinitis (AR) was formulated by Hansel in 1929 [1]. It is a symptomatic nasal disorder caused by allergen exposure through an IgE-mediated immune response against allergens. AR can be subdivided into intermittent (symptoms $<4$ days per week or for $<4$ weeks) and persistent disease (symptoms $>4$ days per week or for $>4$ weeks) and is further characterized according to severity as mild or moderate/severe [2].

The nasal passage and paranasal sinuses are an integral part of the respiratory tract and patients may have rhinitis without sinusitis, but not sinusitis without rhinitis, hence the term rhinitis has been replaced in modern ENT literature by the more accurate term rhinosinusitis [3]. AR and Asthma are linked epidemiologically, pathologically, physiologically and therapeutically and can be considered as a manifestation of a single inflammatory airway syndrome [4]. Most patients with Asthma have rhinitis suggesting the concept of "one airway, one disease" [5]. AR is more prevalent than Asthma and a

\footnotetext{
* Correspondence: ravindernatt@hotmail.com

'Department of Otolaryngology, Leighton Hospital, Crewe CW1 4QJ, UK Full list of author information is available at the end of the article
}

European population study was reported to have an AR prevalence rate of $25 \%$ [6]. AR usually precedes Asthma and can be considered as risk factor for the development of Asthma. Rhinitis exists in up to $80 \%$ of Asthma patients and frequently exacerbates Asthma and increases the risk of Asthma attacks, but the prevalence of Asthma in patients with rhinitis varies from $10-40 \%$ [7]. AR and Asthma are chronic respiratory diseases that cause major disability worldwide including impaired sleep, school, work and quality of life and are associated with substantial economic costs [8].

The aetiology of AR is multi-factorial and the diagnostic and therapeutic choices remain diverse. The aim of this questionnaire survey was to highlight the treatment trends in the management of AR amongst UK-based otolaryngologists.

\section{Methods}

A questionnaire (Appendix 1) was emailed via ENT UK to the email addresses of all registered consultant members of the British Association of Otorhinolaryngologists - Head and Neck Surgeons (BAO-HNS). Survey recipients were asked 1) about their familiarity with the

C Biomed Central

(c) 2011 Natt et al; licensee BioMed Central Ltd. This is an Open Access article distributed under the terms of the Creative Commons Attribution License (http://creativecommons.org/licenses/by/2.0), which permits unrestricted use, distribution, and reproduction in any medium, provided the original work is properly cited. 
Allergic Rhinitis and Its Impact on Asthma (ARIA) guidelines in collaboration with the World Health Organisation (WHO), 2) about the type of investigations, treatment regimes and follow-up arrangements for AR patients and 3) about whether they give to patients advice leaflets on life style changes including education and allergen avoidance. All participants had the opportunity to answer anonymously.

\section{Results}

A total of 551 questionnaires were emailed. There were 309 replies (56\% response rate). All consultants were familiar with the association between AR and Asthma but only $63 \%$ of the respondents were familiar with the ARIA guidelines. Seventy seven (25\%) of otolaryngologists managed AR patients of which a $20-30 \%$ proportion had associated symptoms or a diagnosis of Asthma (Figure 1).

The commonest investigation requested was skin prick testing ( $81 \%$ of respondents). Only nine consultants (3\%) arranged pulmonary spirometry (Figure 2).

Fifty six per cent of otolaryngologists preferred the management pathway of starting treatment and then discharging AR patients to General Practitioners (GPs) for further follow-up. However three (1\%) consultants managed and subsequently referred AR patients to a respiratory physician (Figure 3 ).

In total two hundred and forty (78\%) of otolaryngologists provided patient leaflets on life-style changes including education and practical tips on allergens avoidance. (Figure 4)

\section{Discussion}

AR is a multi-factorial disease with a worldwide disabling effect on all individuals irrespective of age and ethnic background. In 2001 the ARIA in collaboration with the WHO workshop published guidelines for healthcare professionals in order to highlight the latest updates on the aetiology of AR emphasizing the

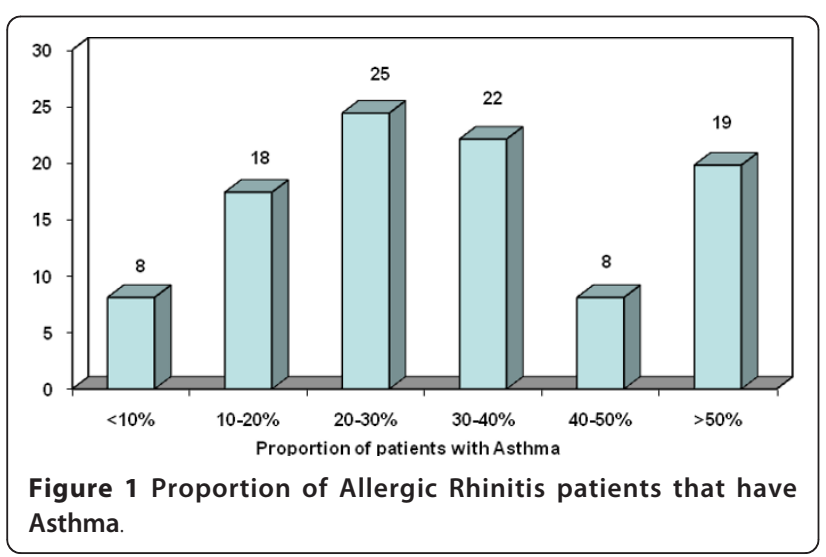

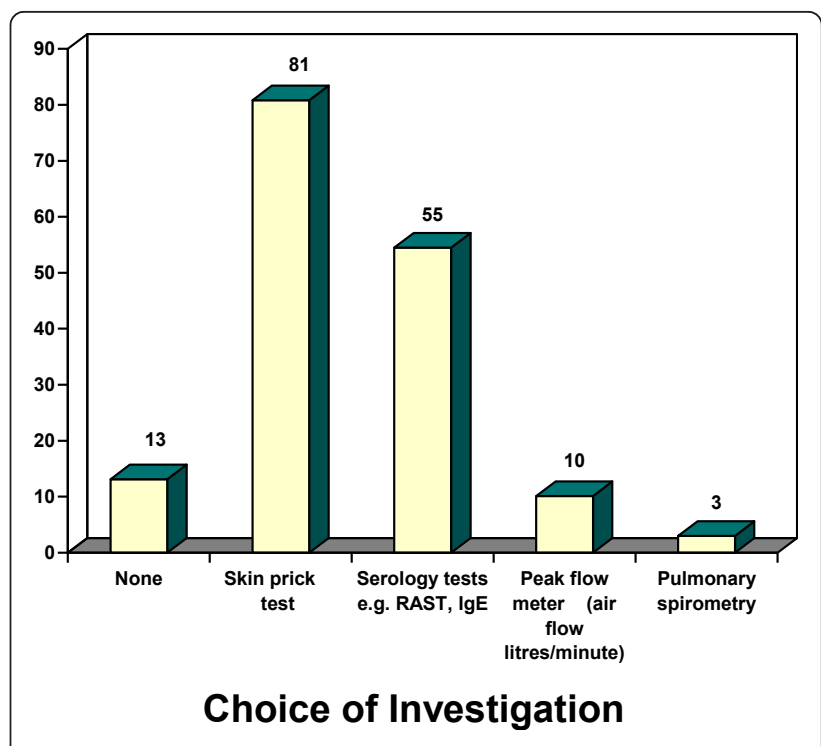

Figure 2 Investigations for Allergic Rhinitis

association between AR and Asthma and proposing a management algorithm [2]. In 2008 a further update incorporated evidence based practice and the Grading of Recommendations Assessment, Development and Evaluation (GRADE) Working Group methodology with a focus on the prevention of allergic and chronic respiratory diseases [9].

Risk factors for AR include a combination of environmental and genetic interactions [10]. The diagnosis of AR is based upon a thorough history of allergic symptoms and diagnostic investigations. The European Academy of Allergiology and Clinical Immunology, the US Joint Council of Allergy and Asthma and the WHO recommend the use of skin prick testing for AR, which is preferred by the majority of UK otolaryngologists (81\%) [11].

An overwhelming 99\% of UK ENT consultants use intra-nasal steroids to treat AR. This trend is supported by several studies demonstrating that intra-nasal steroids

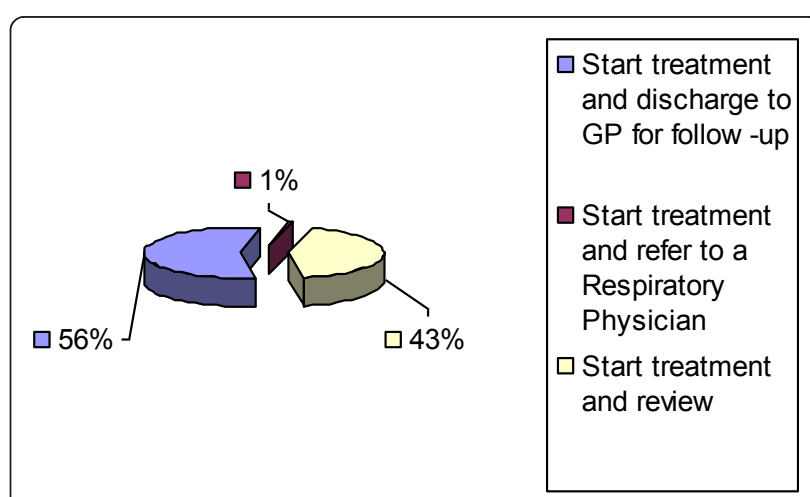

Figure 3 Management Pathway for Allergic Rhinitis 


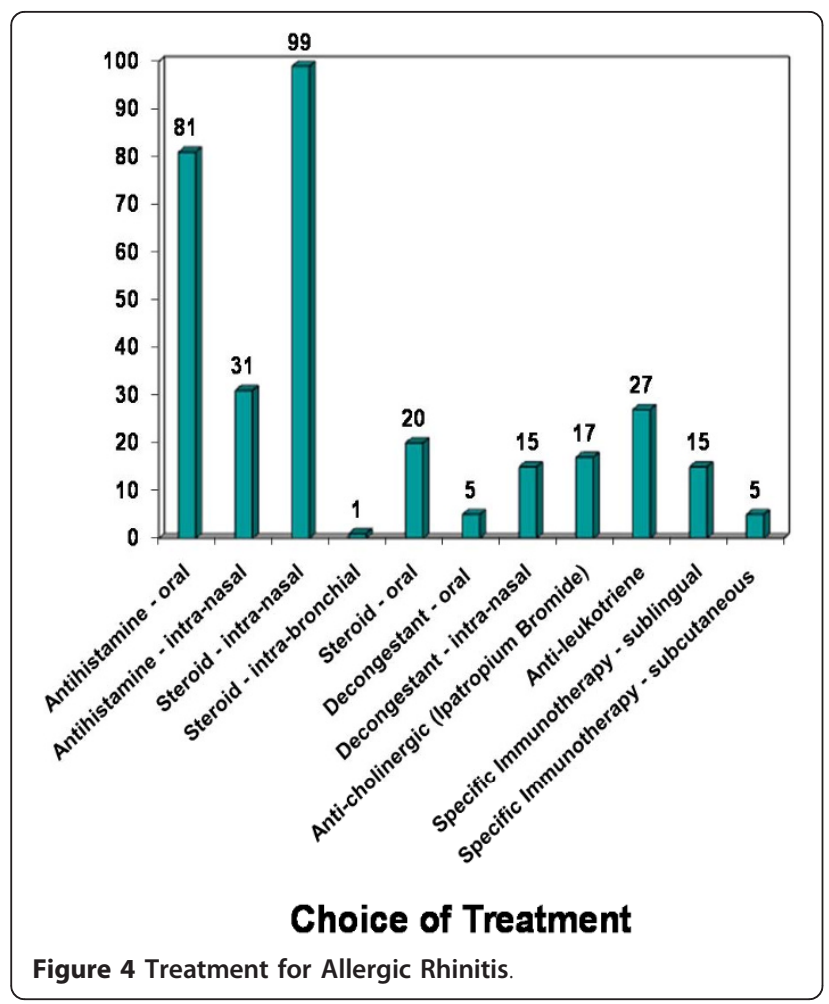

are the most efficacious and cost effective first line treatment for AR $[12,13]$.

Allergen specific immunotherapy for AR was first described in 1911 by Noon and involves the administration of a gradually increasing quantity of an allergen extract [14]. Patients are selected with demonstrated specific IgE antibodies to known allergens. In the USA the subcutaneous route is the only licensed route of administration. Interestingly $15 \%$ of UK otolaryngologists used sublingual and 5\% used subcutaneous forms of immunotherapy. There is increasing evidence supporting the use of allergen immunotherapy in AR. Unlike pharmacotherapy, the clinical benefits are likely to be sustained for many years after discontinuation of treatment [15]. Wilson et al in a cochrane review showed sublingual immunotherapy to be a safe and effective option in managing AR [16]. Furthermore, Calderon et al in a recently published meta-analysis advocate the use of allergen injection immunotherapy as an effective treatment with a low risk of adverse effects in the management of AR [17]. However, further studies are required to evaluate significant differences between these two routes. Allergen specific immunotherapy is not recommended in patients with severe or uncontrolled Asthma because of risk of adverse bronchial reactions [18].

The importance of educating patients or carers with advice leaflets with information regarding AR including allergen avoidance cannot be over emphasised and was actively supported by $78 \%$ of responders of this survey. This enables individuals to be actively involved in the management of their disease resulting in an overall improvement in patient satisfaction, treatment compliance and outcomes [19]. Such practice is endorsed by the General Medical Council (GMC) through its guidance on good medical practice for doctors [20].

Interestingly, only $3 \%$ of otolaryngologists arranged pulmonary spirometry and $1 \%$ of all respondents referred AR patients to a respiratory physician for management of any associated lower respiratory tract pathology. Several studies though have demonstrated that AR patients with no underlying Asthma do have impaired pulmonary function and reversible airway obstruction $[21,22]$. In addition, studies have revealed that AR is linked to an increased use of Asthma related medical services and that the treatment of either AR or that of Asthma can alleviate the symptoms of the other and hence reduce the number of days off school and work and costs of utilising medical services loss of employment productivity $[23,24]$. Furthermore, greater awareness of the economic burden of AR would assist healthcare providers in establishing priorities for the allocation of their limited resources and ultimately ensure cost and clinical effective outcomes [25].

\section{Conclusion}

This survey demonstrates as expected a diverse approach to the management of Allergic Rhinitis. An interesting finding of the survey is that despite good evidence on the relationship between Asthma and AR, most otolaryngologists often do no think "outside the specialty", for example they would rarely use spirometry as a diagnostic aid.

A combined treatment strategy of allergen avoidance, pharmacotherapy, immunotherapy and education applied to patients with AR and concomitant Asthma as recommended by the ARIA guidelines may reduce medical treatment costs and improve symptom control and quality of life.

\section{Conflicts of and Competing interests}

The authors declare that they have no competing interests.

\section{APPENDIX 1: Allergic Rhinitis E-mail Questionnaire}

Dear colleague,

Pease could you complete this survey with your responses and return it by clicking the SUBMIT button below. We thank you for your valuable time in completing this survey.

1. Are you familiar with the association between Allergic Rhinitis and Asthma? 
- Yes

- No

2. Are you familiar with the Allergic Rhinitis and its impact on Asthma (ARIA) guidelines in collaboration with the World Health Organisation?

- Yes

- No

3. What proportion of your patients with Allergic Rhinitis have got symptoms or diagnosis of Asthma?

- $<10 \%$

- $10-20 \%$

- $20-30 \%$

- $30-40 \%$

- $40-50 \%$

- $>50 \%$

4. If you suspect Allergic Rhinitis what investigations would you consider (you may tick one, or more of the following)?

- None

- Skin prick test to known allergens

- Serology tests e.g. RAST, IgE

- Peak flow meter (air flow litres/minute)

- Pulmonary spirometry

5. If you suspect Allergic Rhinitis in a patient which of the following management plans would you consider?

- Start treatment and review

- Start treatment and discharge patient to GP for follow-up

- Start treatment and refer to a Respiratory Physician

6. If you suspect Allergic Rhinitis which of the following would you use for treatment (you may tick one, or more of the following)?

- Antihistamine - oral

- Antihistamine - intra-nasal

- Steroid - intra-nasal

- Steroid - intra-bronchial

- Steroid - oral

- Decongestant - oral

- Decongestant - intra-nasal

- Anti-cholinergic (Ipatropium Bromide)

- Anti-leukotriene

- Specific Immunotherapy - sublingual

- Specific Immunotherapy - subcutaneous

7. How long do you prescribe nasal sprays for

- 3 months

- 6 months

- >6 months

8. What is the frequency of nasal spray administration do you prescribe (you may tick one, or more from the following)?

- Two puffs once a day

- Two puffs twice a day
- Other (please specify)

9. Do you provide leaflets for patients about life-style changes including education and avoidance of allergen $(\mathrm{s})$ ?

- Yes

- No

\section{Acknowledgements}

Presented at the $22^{\text {nd }}$ Congress of the European Rhinologic Society (ERS) and the $27^{\text {th }}$ International Symposium of Infection and Allergy of the Nose (ISIAN), Crete, $19^{\text {th }}$ June 2008.

\section{Author details}

'Department of Otolaryngology, Leighton Hospital, Crewe CW1 4QJ, UK. 2Department of Otolaryngology, Royal Liverpool University Hospital, Liverpool L7 8XP, UK. ${ }^{3}$ Department of General Medicine, Leighton Hospital, Crewe CW1 4QJ, UK. ${ }^{4}$ Division of Primary Care, University of Liverpool,

Liverpool L69 3BX, UK.

\section{Authors' contributions}

RSN: Primary Author of manuscript. PDK: Assistant Author of manuscript and Editing. EGT: Contribution to Literature Search and Proof Reading. AK: Senior Clinician and contribution to Proof Reading and Editing. DKN: Assisted writing manuscript and designing questionnaire. All authors read and approved the final manuscript.

Received: 10 August 2010 Accepted: 11 April 2011

Published: 11 April 2011

References

1. Hansel F: Clinical and histopathologic studies of the nose and sinuses in allergy. J Allergy 1929, 1:43-70.

2. Bousquet J, Van Cauwenberge $P$, Khaltaev N: Allergic Rhinitis and its impact of Asthma. J Allergy Clin Immunol 2001, 108:147-334.

3. Fokkens W, Lund V, Mullol J: European position paper on rhinosinusitis and nasal polyps 2007. Rhinology Supp/ 2007, 20:1-136.

4. Cauwenberge P, Watelet J, Zele T, Wang D, Toskala E, Durham S, et al: Does rhinitis lead to Asthma? Rhinol 2007, 45:112-121.

5. Bousquet J, Vignola AM, Demoly P: Links between rhinitis and Asthma. Allergy 2003, 58:691-706.

6. Bachau V, Durham SR: Prevalence and rate of diagnosis of Allergic Rhinitis in Europe. Eur Respir J 2004, 24:758-764.

7. Leynaert B, Neukirch C, Kony S, Guenegou A, Bousquet J, Aubier M, et al: Association between Asthma and rhinitis according to atopic sensitisation in a population based study. J Allergy Clin Immunol 2004, 113:86-93.

8. Blaiss MS: Medical and economic dimensions linking Allergic Rhinitis and Asthma. Allergy Asthma Proc 2002, 23:223-227.

9. Bousquet N, Khaltaev A, Cruz J, Denburg W, Fokkens A, Togias T, et al: Allergic Rhinitis and its Impact on Asthma (ARIA) 2008 update (in collaboration with the World Health Organization, GA ${ }^{2}$ LEN and AllerGen). Allergy 2008, 63(Suppl 86):8-160.

10. Lee H, Park S, Chung S, Woo J, Chae S, Lee S, et al: Interleukin-18/-607 gene polymorphism in Allergic Rhinitis. Int J Pediatr Otorhinolaryngol 2006, 70:1085-1088.

11. Bousquet J, Lockey R, Malling H: WHO Position Paper. Allergen Immunotherapy: therapeutic vaccines for allergic disease. J Allergy Clin Immunol 1998, 102:558-562.

12. Weiner J, Abramson M, Puy R: Intranasal corticosteroids versus oral $\mathrm{H} 1$ receptor antagonists in Allergic Rhinitis: systematic review of randomised controlled trials. BMJ 1998, 317:1624-1629.

13. Bhatia S, Baroody F, Detineo M, Naclerio R: Increased nasal airflow with budesonide compared with desloratidine during the allergy season. Arch Otolaryngol Head Neck Surg 2005, 131:223-228.

14. Noon L: Prophylactic inoculation against hay fever. Lancet 1911, 1:1572-1573.

15. Wallace D, Dykewizc M, Bernstein D, Moore J, Cox L, Khan D, et al: The diagnosis and management of rhinitis: An updated practice parameter. Allergy Clin Immunol Suppl 2008, 122:1-84. 
16. Wilson $D$, Torres $M$, Durham S: Sublingual immunotherapy for Allergic Rhinitis. Cochrane Database of Systematic Reviews 2003, 2.

17. Calderon MA, Alves B, Jacobson M, Hurwitz B, Sheikh A, Durham S: Allergen injection immunotherapy for seasonal Allergic Rhinitis. Cochrane Database of Systematic Reviews 2007, 1.

18. Winther $L$, Arnved J, Malling H, Nolte H, Mosbech H: Side-effects of allergen-specific immunotherapy: A prospective multi-centre study. Clin Exp Allergy 2006, 36:254-260.

19. Dykewicz M, Fineman S, Niklas R, Lee R, Moore J, Li J, et al: Joint task fork algorithm and annotations for diagnosis and management of rhinitis. Ann Allergy Asthma Immunol 1998, 81:469-473.

20. Good Medical Practice: General Medical Council Publication; 2006.

21. Kessel A, Halloun H, Bamberger E, Kugelman A, Toubi E: Abnormal spirometry in children with persistent Allergic Rhinitis due to mite sensitization: The benefit of nasal corticosteroids. Pediatr Allergy Immunol 2007, 19:161-166.

22. Ciprandi G, Cirillo I, Pistorio A: Impact of Allergic Rhinitis on Asthma: effects on spirometric parameters. Allergy 2008, 63:255-260.

23. Price $D$, Zhang $Q$, Kocevar $V$, Yin $D$, Thomas M: Effect of concomitant diagnosis of Allergic Rhinitis on Asthma-related health care use by adults. Clin Exp Allergy 2005, 35:282-287.

24. Halpern M, Schimer J, Richner R, Guo C, Togias A: Allergic Rhinitis: A potential cause of increased Asthma medication use, costs and morbidity. J Asthma 2004, 41:117-126.

25. Schoenwetter WF, Dupclay L, Appajoysyula S, Botteman M, Pashos C: Economic impact and quality of life burden of Allergic Rhinitis. Curr Med Res Opin 2004, 20:305-317.

\section{Pre-publication history}

The pre-publication history for this paper can be accessed here: http://www.biomedcentral.com/1472-6815/11/3/prepub

doi:10.1186/1472-6815-11-3

Cite this article as: Natt et al:: Treatment trends in allergic rhinitis and asthma: a British ENT survey. BMC Ear, Nose and Throat Disorders 2011 11:3.

\section{Submit your next manuscript to BioMed Central and take full advantage of:}

- Convenient online submission

- Thorough peer review

- No space constraints or color figure charges

- Immediate publication on acceptance

- Inclusion in PubMed, CAS, Scopus and Google Scholar

- Research which is freely available for redistribution

Submit your manuscript at www.biomedcentral.com/submit 